\title{
SIMULADOR PHET E O ENSINO DA TABUADA NA EDUCAÇÃO BÁSICA: RELATO DE EXPERIÊNCIA
}

\author{
SIMULADOR PHET Y LA ENSEÑANZA DE LA TABUADA EN LA EDUCACIÓN \\ BÁSICA: RELATO DE EXPERIENCIA
}

\section{PHET SIMULATOR AND THE TABLE TEACHING IN BASIC EDUCATION: EXPERIENCE REPORT}

\author{
Lilian de Fatima Oliveira FALCHI ${ }^{1}$ \\ Ivan FORTUNATO ${ }^{2}$
}

\begin{abstract}
RESUMO: O presente trabalho foi desenvolvido com a finalidade de incentivar professores do ensino fundamental a usar o simulador PhET junto com seus estudantes, como meio para potencializar a aprendizagem da tabuada. O simulador é um facilitador de aprendizado, que visa desenvolver simulações para o ensino de ciências, matemática, física e química. O trabalho traz o relato do uso do simulador com os alunos do terceiro ano do ensino fundamental, aplicado sob a supervisão conjunta pelos pesquisadores e as professoras titulares. O uso do simulador com os alunos ocorreu em setembro e outubro de 2016 com aulas semanais. Foram aulas práticas no laboratório de informática da escola, onde os alunos puderam explorar o simulador, bem como avançar as fases de acordo com seu desempenho. Essa experiência ajudou a compreender a necessidade de se transformar a educação e incorporar a tecnologia digital no ensino/aprendizado para motivar e facilitar a aprendizagem.
\end{abstract}

PALAVRAS-CHAVE: Informática na educação. Aprendizagem. Novas metodologias.

RESUMEN: El presente trabajo fue desarrollado con la finalidad de incentivar a profesores de la enseñanza fundamental a usar el simulador PhET junto con sus estudiantes, como medio para potenciar el aprendizaje de la tabla. El simulador es un facilitador de aprendizaje, que busca desarrollar simulaciones para la enseñanza de ciencias, matemáticas, física y química. El trabajo trae el relato del uso del simulador con los alumnos del tercer año de la enseñanza fundamental, aplicado bajo la supervisión conjunta por los investigadores y las profesoras titulares. El uso del simulador con los alumnos ocurrió en septiembre y octubre de 2016 con clases semanales. Se realizaron clases prácticas en el laboratorio de informática de la escuela, donde los alumnos pudieron explorar el simulador, así como avanzar las fases de acuerdo con su desempeño. Esta experiencia ayudó a comprender la necesidad de

\footnotetext{
${ }^{1}$ Instituto Federal de São Paulo (IFSP) Itapetininga - SP - Brasil. Especialista em Informática Aplicada à Educação. E-mail: lilianfalchy@gmail.com

2 Instituto Federal de São Paulo (IFSP) Itapetininga - SP - Brasil. Coordenadoria de Formação Pedagógica \& Universidade Federal de São Carlos (UFSCar) Sorocaba - SP - Brasil. Programa de PósGraduação em Educação. ORCID: <http://orcid.org/0000-0002-1870-7528>. E-mail: ivanfrt@yahoo.com.br
} 
transformar la educación e incorporar la tecnología digital en la enseñanza / aprendizaje para motivar y facilitar el aprendizaje.

PALABRAS CLAVE: Informática en la educación. Aprendizaje. Nuevas metodologías.

ABSTRACT: This research was developed with the purpose of encouraging elementary school teachers to use the PhET simulator with their students as a means to enhance the learning of the table. The simulator is a learning facilitator, which aims to develop simulations for teaching science, mathematics, physics and chemistry. This paper reports the use of the simulator with the students of the third year of elementary school, applied under the joint supervision by the researchers and the schoolteachers. The use of the simulator with the students occurred in September and October of 2016 with weekly classes. Those were practical classes in the school's computer lab, where students were able to explore the simulator as well as advance the phases according to their performance. This experience helped to understand the need to transform education and incorporate digital technology into teaching / learning to motivate and facilitate learning.

KEYWORDS: Informatics in education. Learning. New methodologies.

\section{Introdução}

Este trabalho traz o relato de uma experiência educativa com o uso do simulador PhET (https://PhET.colorado.edu/pt_BR/), um facilitador de aprendizado desenvolvido pela Universidade do Colorado, em 2002. Foi criado pelo projeto Physics Educacional Technology (PhET), que visa pesquisar e desenvolver simulações para o ensino de ciências, matemática, física e química. O simulador PhET possibilita aos professores mesclarem aulas teóricas e práticas, visto que o uso da tecnologia torna as aulas mais dinâmicas e possibilita o aprendizado de forma interativa. Além disso, os professores podem usar o simulador como ferramenta de ensino no laboratório de informática da escola, sem a necessidade do uso da internet no momento da aula. Isso porque é possível instalar o simulador no computador ou dispositivo eletrônico, desde que este possua um aplicativo Java, Flash ou HTML5, que permite armazenar aplicações da internet para uso offline.

A quantidade de simulações prontas que favorecem o aprendizado de forma descontraída e ao mesmo tempo interessante, na forma de jogos, fazem do simulador PhET um local de potenciais aprendizagens. Em uma experimentação particular, o filho da pesquisadora demonstrou grande interesse pela simulação e melhorou bastante seu desempenho escolar em matemática, especificamente na tabuada. Teria sido um acaso? 
Era preciso, portanto, verificar sua aceitação pelo alunado e sua efetiva ação pedagógica. Em parceria com Secretaria Municipal de Educação de Itapetininga (cidade no sudoeste paulista), chegamos à Escola Hilda Weiss como lugar interessado no projeto, pois a escola já realiza anualmente uma olimpíada interna de tabuadas, dentre outros projetos voltados ao ensino mais dinâmico e interativo.

Em agosto de 2016, os professores, coordenadores e direção da escola tomaram conhecimento das particularidades do projeto, discriminadas por meio de um plano de aula elaborado por nós, com o objetivo de incentivar os professores a diversificarem suas aulas, incluindo atividades no laboratório de informática. O uso do simulador com os alunos foi realizado na sala de informática da referida escola em aulas semanais, durante dois meses do segundo semestre do ano de 2016. Foram duas turmas distintas do terceiro ano, sendo que as professoras titulares foram ensinadas a trabalharem com o simulador. Para acompanhar os resultados do projeto, participamos de aulas, colhemos depoimentos das professoras, da diretora e retornamos à escola no semestre seguinte à realização do projeto, para verificar possíveis resultados e desdobramentos da ação.

Com este trabalho, a plataforma PhET foi introduzida no ensino fundamental com objetivo de incentivar - professores e estudantes - a fazerem uso das Tecnologias Digitais da Informação e Comunicação (TDIC) no processo formal de ensinoaprendizagem. Como objetivo específico, a proposta foi verificar a viabilidade de se usar um simulador para o ensino-aprendizado da tabuada no primeiro ciclo do ensino fundamental. Para alcançar os objetivos propostos, este artigo foi desenvolvido em três partes. A primeira, a análise de literatura, foi motivada pela busca de trabalhos cujos autores acreditam no uso das tecnologias para o ensino, os avanços e os principais entraves para que a tecnologia se firme na educação. Em seguida, apresenta-se o relato da experiência desenvolvida na Escola Hilda Weiss, descrevendo as etapas de condução do projeto. Na sequência, em avaliando a experiência, ponderamos o uso da plataforma PhET no auxílio do ensino da tabuada, a partir dos relatos e questionários, bem como dos momentos de observação in loco. Ao final, espera-se que este trabalho sensibilize o professorado para que as TDIC sejam incorporadas nas práticas educativas. Além da sensibilização, este trabalho trata da importância de se planejar uma aula, de se buscar novos meios para atingir objetivos pedagógicos, bem como a importância de se avaliar uma experiência para aprimorar o trabalho docente. 


\title{
Primeira parte: revisão de literatura
}

\begin{abstract}
A escola é uma instituição mais tradicional que inovadora. A cultura escolar tem resistido bravamente às mudanças. Os modelos de ensino focados no professor continuam predominando, apesar dos avanços teóricos em busca de mudanças do foco do ensino para o de aprendizagem. Tudo isto nos mostra que não será fácil mudar esta cultura escolar tradicional, que as inovações serão mais lentas, que muitas instituições reproduzirão no virtual o modelo centralizador no conteúdo e no professor do ensino presencial (MORAN, 2013, p. 2).
\end{abstract}

Já não é mais novidade anotar que muitos pesquisadores, gestores escolares, professores, estudantes e familiares etc. acreditam que o uso da tecnologia se estabeleça e se firme na educação, apesar das resistências e restrições. Particularmente no caso do professorado, essa resistência pode ser estabelecida pela inabilidade, desconhecimento das ferramentas ou, até mesmo, falta de confiança no uso da tecnologia para o ensino/aprendizado. Não obstante, a falta de equipamentos em funcionamento nas escolas, em geral, também desmotiva o professor, ajudando a fortalecer as resistências às tecnologias.

Mesmo assim, é preciso continuar buscando meios de inserir as TDIC na educação escola, pois, conforme anotou Souza (2015), ela já pode ser considerada eficaz, sendo que "[...] a sua evolução ao longo da história foi, e continua sendo, muito interessante e respeitável na divulgação do ensino" (p. 38). Assim, entendemos que os professores podem encontrar nas TDIC novas metodologias capazes de instigar o interesse dos alunos em aprender.

Como uma possível estratégia de inserção das tecnologias na escola, buscamos, neste trabalho, apresentar o jogo digital como potencial estímulo pedagógico, tanto aos professores quanto aos estudantes. Pensamos, assim, no simulador PhET como um repositório de jogos, capaz de responder às ideias tecidas por Moran (2015), quando anotou que:

\footnotetext{
Para gerações acostumadas a jogar, a linguagem de desafios, recompensas, de competição e cooperação é atraente e fácil de perceber. Os jogos colaborativos e individuais, de competição e colaboração, de estratégia, com etapas e habilidades bem definidas se tornam cada vez mais presentes nas diversas áreas de conhecimento e níveis de ensino (MORAN, 2015, p. 4).
} 
Já se tornou senso-comum afirmar que as crianças e os jovens nasceram na era tecnológica, fazendo uso, desde muito cedo, dos computadores e celulares (entre outros dispositivos). Além disso, são fascinados por jogos. Logo, sendo o $\mathrm{PhET}$ uma ferramenta que ensina através do jogo, acredita-se que esta pode motivar as crianças e os jovens para o uso do entretenimento como forma de estudo.

Não é proposto que o professor abandone seu método de ensino em detrimento da tecnologia, mas, que encontre novas possibilidades para diversificar suas aulas. No caso do simulador, por exemplo, seu uso deve ser entendido como um complemento às aulas regulares, ampliando as possibilidades de aprendizagem. Isso está alinhado com o exposto por Silva (2013):

\begin{abstract}
A tecnologia já entrou na sala de aula. O aluno está receptivo a ela, cabe ao professor aprender como introduzir pedagogicamente esses recursos em sua prática pedagógica, pois a escola precisa se aproximar do ritmo da sociedade em que o aluno está inserido e para que a prática do professor seja dinâmica, onde possam ser vivenciadas novas práticas com o uso da tecnologia em sala de aula, é necessário que ele conheça os benefícios na aprendizagem proporcionados quando são inseridos nas aulas os recursos tecnológicos (SILVA, 2013, p. 2).
\end{abstract}

Particularmente sobre o ensino de matemática, incluindo a tabuada, nota-se que este é caracterizado por um processo gradativo, no qual o aluno aprende por repetições e muito treino. Para tanto, o professor conta com o auxílio de livros didáticos e muitos exercícios realizados no caderno, como o método tradicional de elencar a tabuada multiplicando sucessivamente do primeiro ao décimo número. O aluno, por sua vez, fixa os resultados realizando multiplicações sucessivas. De acordo com Martins (2009):

O desenvolvimento das Tecnologias de Informação e Comunicação (TIC) veio acrescentar a todo esse movimento uma verdadeira revolução no ensino da disciplina. Numa Sociedade marcada pela utilização massiva das TIC, a Matemática surge como uma área disciplinar essencial para a formação e integração dos jovens na vida profissional activa e aqui reside a razão fundamental da importância que a Sociedade, em geral, atribui à disciplina. Daí a preocupação dos responsáveis pelo processo educativo, pela constante procura de resultados positivos e explicações para o insucesso na Matemática (MARTINS, 2009, p. 1).

O uso das TDIC para o ensino-aprendizado de matemática é muito interessante e deve ser valorizado pela escola, pois possibilita o acesso a jogos e simuladores prontos, disponíveis e por vezes gratuitos, como o PhET, com os quais os estudantes podem 
interagir e aprender. Sobre a plataforma PhET, especificamente, esta é simples de acessar e interagir, pois é aberta ao público em geral, não sendo necessário cadastro, login ou senha.

Ao acessar o site da plataforma, e clicar na opção "Entre aqui e Simule", uma lista muito grande de simulações é disponibilizada. Para a simulação da tabuada, especificamente, é preciso procurar por "aritmética". Nesta, as operações apresentadas são: multiplicar, fatorar e dividir (figura 01), sendo que cada operação apresenta três níveis de dificuldade e, em cada nível, o usuário pode optar por habilitar ou não o relógio. O usuário pode iniciar o simulador em qualquer nível, sendo que se optar pelo nível 1 ou 2, após os acertos, será encaminhado automaticamente ao nível seguinte (figura 02). O nível 1 apresenta multiplicações do número 1 ao 6 (figura 03), o nível 2 apresenta multiplicações do número 1 ao 9 e o nível 3 apresenta multiplicações do 1 ao 12.

Figura 01: tela multiplicar

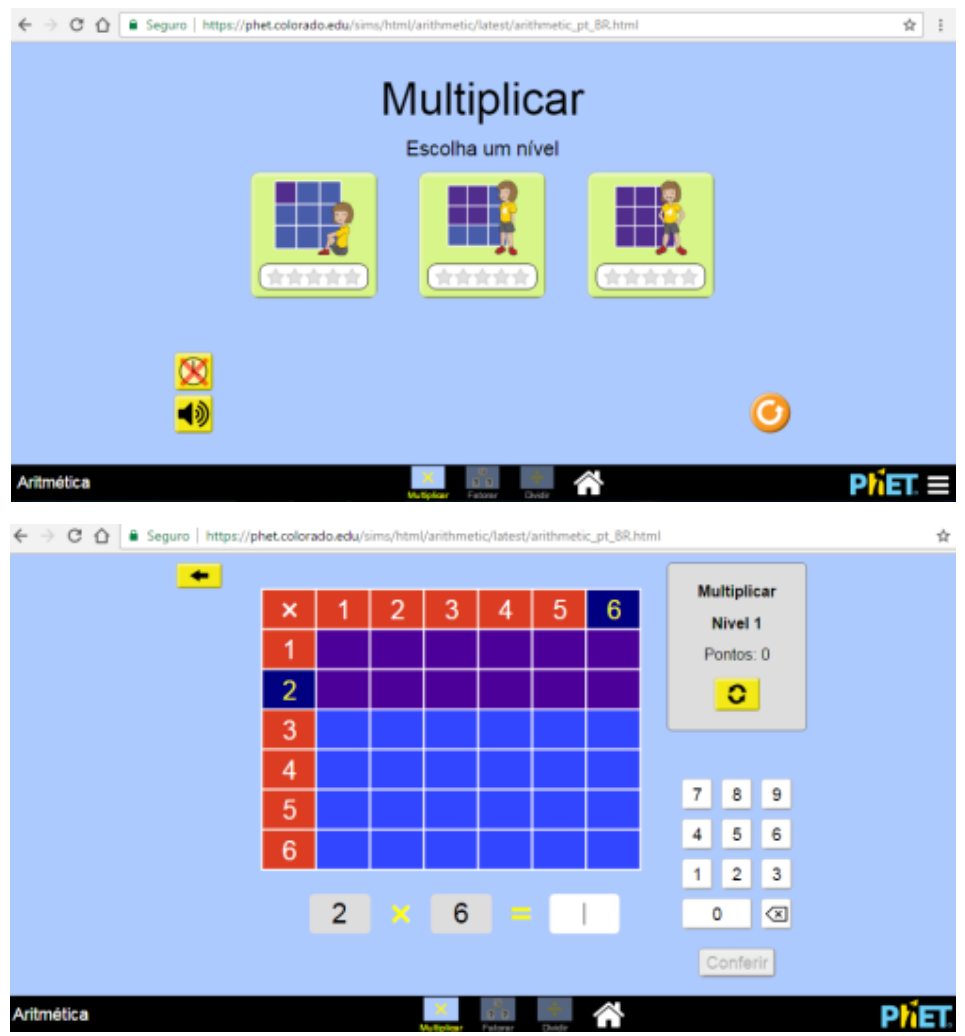

Fonte: phet.colorado.edu (2017) 
Figura 02: tela resultado da tabuada

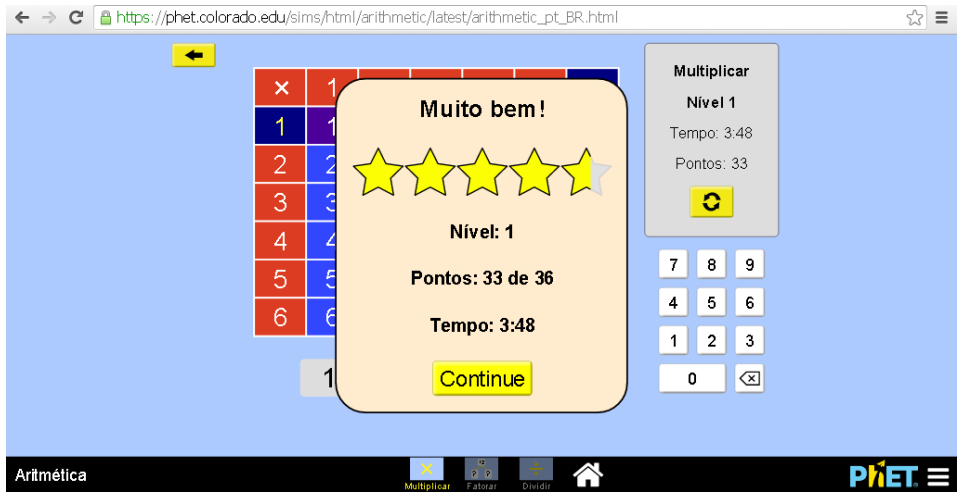

Fonte: phet.colorado.edu (2017)

Figura 03: tela resultado da tabuada

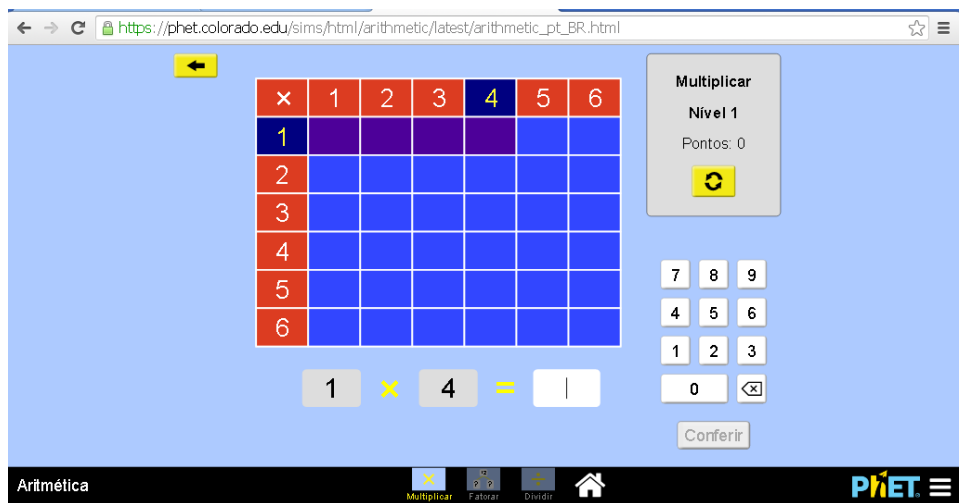

Fonte: phet.colorado.edu (2017)

\section{Segunda parte: relato da experiência Hilda}

[...] é preciso rever muita coisa sobre a atividade docente, afinal, temos uma observação muito clara de que nosso leque de ação didática é algo concebido para outro tempo, de forma praticamente alienada das evoluções culturais, mesmo que se mudem as carteiras de lugar... Foi, então, pensando e repensando sobre técnicas e utensílios de ensino - a dimensão instrumental da didática -, ponderando se estava imprimindo formas de introdução aos conteúdos curriculares que não se inscreviam no mundo dos estudantes de pedagogia, e/ou se estava conservando velhas práticas em detrimento das novas tecnologias [...] (FORTUNATO, 2016, p. 712).

Poderiam as tecnologias digitais, os computadores, a internet [...] ajudar na transformação da escola? Seriam importantes instrumentos para a didática? A literatura, que pressupõe sua eficácia (SOUZA, 2015), teria respaldo no cotidiano escolar? Foi pensando sobre essas questões que levamos o simulador PhET para dentro da escola, 
como forma de compartilhar com professores e estudantes uma - dentre tantas possibilidades de intervenção tecnológica na educação.

Como afirma Moran (2013), a cultura escolar tem resistido às mudanças e os moldes de ensino ainda são voltados para o professor e não para a aprendizagem, porém, com a intervenção tecnológica, a intenção seria incentivar os professores a buscarem outras ferramentas para fazer a diferença no aprendizado de seus alunos.

Dessa forma, em agosto de 2016, o simulador PhET foi apresentado aos professores, coordenador e direção da escola Hilda Weiss, na região periférica de Itapetininga, por meio de um plano de aula para o $3^{\circ}$ ano, contendo um cronograma para a aplicação do projeto também foi estipulado. Na ocasião, fomos até o laboratório de informática da escola, onde as professoras do $3^{\circ}$ ano puderam aprender a acessar e utilizar as ferramentas do PhET, em uma sessão de treinamento que não durou mais que meia hora.

Assim, o uso do PhET com os alunos teve início no dia nove do mês seguinte. $\mathrm{O}$ simulador já estava salvo na área de trabalho do computador, facilitando o acesso dos estudantes. Isso demonstrou vontade e interesse por parte da escola em ver o funcionamento do projeto, o que reporta à ideia de Martins (2009) sobre a preocupação da equipe escolar em obter resultados positivos para o ensino/aprendizado da matemática.

Essa turma do $3^{\circ}$ ano foi acompanhada por nós durante todas as semanas de aplicação do projeto, permitindo que este relato de experiência fosse mais vivo, pois, pudemos interagir com a professora e com os estudantes, no momento em que faziam uso do simulador PhET para o estudo da tabuada.

De início, era perceptível que os alunos estavam ansiosos e prestaram bastante atenção nas explicações sobre o uso do simulador. A ansiedade mostra o quanto os alunos estão receptivos à tecnologia, conforme vimos em Silva (2013). Foi preciso dividir a turma em duplas, devido à quantidade insuficiente de computadores em funcionamento. Isso causou certo desconforto por parte dos alunos, pois queriam escolher os pares que tinham mais afinidade e a professora optou por agrupar aleatoriamente os alunos. Mas, logo estavam interagindo com o computador, ratificando a ideia de que essa geração tem muito interesse e afinidade com os dispositivos digitais.

Os primeiros dez minutos, do primeiro encontro, foram de ajustes e explicações. Foi observado que muitos alunos não tinham habilidade com o mouse do computador, mas, logo todos estavam interagindo com o simulador, alguns com mais facilidade, 
outros, nem tanto. A falta de habilidade com o mouse contrapõe a ideia de Moran (2015), demonstrando que nem todas as crianças desta geração tem acesso à tecnologia, nem tão pouco estão familiarizadas aos jogos, ampliando a necessidade de reflexão sobre as afirmações que são feitas a respeito da relação entre os mais novos e o contato com o mundo digital e virtual. Assim, foi interessante notar que os alunos tentavam dar o melhor de si nas contas da tabuada, vibrando com cada acerto e querendo acertar mais e mais. Observamos que algumas crianças faziam cálculos usando os dedos das mãos, outros contavam na própria tela do computador, ampliando as estratégias de aprendizado para a tabuada e, assim, para a própria matemática.

As semanas seguintes foram tranquilas com relação ao uso do simulador, mas, a euforia dos alunos era bonita de se ver, pois já sabiam o porquê de estarem ali. Alguns escolhiam seus pares e outros rejeitavam seus colegas, sendo isso resolvido pela professora, que ajustava as duplas rapidamente. Logo após o início de cada aula, perguntava-se às duplas se gostariam de utilizar lápis e papel para rascunho. Todas aceitavam e já começavam fazer os cálculos no papel. Foi possível observar que a técnica usada pelos alunos não era a mesma, ou seja, alguns elencavam a conta de forma tradicional e outros faziam riscos ou bolinhas para alcançar os resultados, ratificando a ideia de que cada um tem sua estratégia para resolver os problemas da tabuada.

Era nítido o avanço por parte dos alunos com os cálculos a cada semana, pois já estavam familiarizados com o computador e o exercício repetitivo dos cálculos fazia com que memorizassem e aprendessem as contas. $\mathrm{O}$ avanço alcançado pelos alunos mostra o quanto o jogo pode motivar o aprendizado, conforme Moran (2015) havia expressado.

Certo dia, a professora teve a ideia de presentear a dupla que conseguisse atingir o segundo ou terceiro nível do simulador com um kit escolar (caixa de lápis de cor, apontador, borracha e lápis pretos). Para a nossa surpresa, duas duplas chegaram ao terceiro nível do modo multiplicar do simulador na aula de apenas 50 minutos, sendo que ambas foram presenteadas com o kit.

Na quarta semana de uso do simulador, optamos por iniciar no nível um (01) do modo "fatorar". Nesse modelo, a dinâmica é a mesma, com multiplicações sucessivas; o diferencial é que os alunos precisam arrastar o mouse e soltar, fazendo o cálculo de forma a contemplar a multiplicação da linha vertical com a horizontal. A turma rapidamente entendeu a dinâmica da aula, e logo os alunos começaram a interagir com o computador. Desta vez, ao invés de digitar o resultado, era preciso agilidade para 
segurar o mouse e soltar no quadrado correto para a resposta da multiplicação. Esse novo desafio foi muito bem aceito, e as duplas foram realizando os cálculos de forma rápida.

Na quinta e última aula, começamos no nível três (03), com a opção “dividir" do simulador. Isso exigiu mais dos alunos, pois os cálculos são mais complexos. No entanto, todos foram muito dedicados e atentos, realizando rapidamente os problemas propostos, nos surpreendendo com seu ótimo desempenho. Isso mostra o quanto os estudantes estão abertos para receber os recursos tecnológicos. Dessa maneira, mais uma vez pudemos notar que cabe à escola e aos professores inovarem e promoverem o aprendizado de forma a contemplar as inovações tecnológicas à qual vivemos hoje.

\section{Terceira parte: avaliando a experiência}

Com a inclusão do momento de reflexão, podemos efetivamente concluir que o propósito não foi tornar a aula diferente, como frequentemente observamos nas justificativas dadas à inserção, aqui e ali, de exercícios dinâmicos na sala de aula: fazer algo dinâmico tão somente para sair da rotina... E não se adiciona nenhum outro argumento. Daí importante adágio: nenhum instrumento didático dinâmico deve ser utilizado sem a devida contextualização e cuidadoso planejamento prévio, sob o risco de não apenas reduzir ou esvaziar os sentidos pedagógicos de determinada técnica, mas antes de banalizar seu uso, tornando-as enfadonhas e sem nenhum sentido aos participantes (FORTUNATO, 2016, p. 8).

Conforme já foi delineado em outro artigo (FORTUNATO, 2016), toda e qualquer atividade docente deve ser planejada, tendo seus objetivos bem definidos, sendo que a reflexão se faz necessária para aprimorar os métodos e as técnicas. Por isso, para dar conta de compreender a relação entre a TDIC e a educação, a partir da experiência relatada é preciso, portanto, pensar sobre seu planejamento, execução e conclusão. A reflexão deve ser constante por parte dos professores, por isso, nesta experiência, incentivamos as professoras da escola Hilda a pensarem sobre alguns aspectos específicos das atividades.

Isso vai de encontro ao que afirmam Feitosa e Dias (2017), ao anotarem que "a reflexão implicaria a análise da pratica cotidiana considerando as condições sociais em que ela ocorre. Assim, o trabalho docente deve buscar a transformação social dos educandos e da sociedade como um todo interdependente" (p. 25). Para tanto, algumas 
perguntas que fizemos para as professoras, ao longo e ao final do projeto, ajudaram a pensar sobre a ação.

Por exemplo, perguntamos sobre o uso do simulador para auxílio da aprendizagem da tabuada e a percepção delas a respeito do contato dos estudantes com o computador para desenvolverem atividades específicas de aprendizagem - tal como a tabuada. Ambas foram categóricas ao afirmar que o simulador, pelo jogo, proporciona um momento significativo para as crianças, portanto, propicia a aquisição de habilidades e conhecimentos de forma prática e até divertida. Foi relatado, inclusive que, na sala de aula, o desempenho dos estudantes na multiplicação para os exercícios e problemas propostos melhorou bastante, sendo atribuído isso ao uso frequente do simulador.

Ainda, o frequente relato das professoras sobre a expectativa e ansiedade dos alunos nos dias que antecedem a aula, demonstra a boa aceitação dos alunos para o simulador. As professoras expressaram, através de conversa informal, sobre a importância do uso da tecnologia na educação, pois é disso que os alunos gostam e esperam para os dias de hoje (SILVA, 2013). As próprias professoras afirmaram que, cabe a cada professor fazer a integração e inovar suas aulas.

Mesmo no caso da escola Hilda, que está em um bairro periférico e atende uma comunidade carente, com poucos recursos, os alunos anseiam por uma aula diversificada, com uso da tecnologia. Nosso projeto se mostrou bastante valioso, pois pode ter promovido o primeiro contato com o computador para muitos de seus alunos. Isso foi gratificante, pois pudemos, com planejamento e boa vontade da escola, proporcionar àquelas crianças a primeira experiência com a tecnologia de uma forma bastante positiva: com foco no aprendizado.

Ainda, uma das professoras relatou que o projeto permitiu o primeiro acesso à sala de informática do ano, pois, essa sala era de uso prioritário para os alunos de $4^{\circ}$ e $5^{\circ}$ ano. Não só isso, pois como não tinha um plano de aula que contemplasse o uso do computador, não havia sentido pedagógico para usar os computadores. Conforme tal relato, ficou evidente que essa falta de oportunidade para fazer uso do laboratório de informática era um fator de desmotivação para o uso das TDIC como forma de diversificar suas aulas. Nesse caso, nosso projeto ajudou as professoras e a própria escola a repensarem o uso do laboratório de informática.

Sobre a experiência vivenciada através do uso do simulador PhET pelas turmas, as professoras disseram que foram gratificantes e proveitosos os momentos vivenciados 
no laboratório de informática, relatando o quanto seus alunos apreciaram as aulas, bem como o gosto pelo contato com a ferramenta tecnológica. Uma das professoras fez comparações com aulas tradicionais e as aulas no laboratório, dizendo estar muito satisfeita com a receptividade dos alunos com uso da tecnologia.

A cada dia em que acompanhamos a turma, pudemos observar que a aula era mais proveitosa, inclusive, permitindo o estudo da tabuada de forma agradável. Era nítido que o uso do computador foi muito bem aceito por todos: professoras, direção e, especialmente, estudantes. Isso ratifica a ideia de que é preciso incentivar o professorado a diversificar as aulas, tornando-as mais dinâmicas, além de usar a tecnologia em favor do aprendizado.

A realização deste projeto evidenciou que a realização de atividades em parceria com instituições de ensino é um caminho possível para a transformação do ensino/aprendizado. Incluindo, nessa perspectiva, o uso das ferramentas tecnológicas. Para nós, ficou claro que o simulador PhET deve mesmo ser qualificado como um facilitador da aprendizagem, podendo ser usado por profissionais da educação que queiram adentrar o universo de seus alunos, promovendo o aprendizado de maneira lúdica, com características de um jogo.

\section{Considerações finais}

O uso do simulador PhET para tabuada, na escola Hilda Weiss, mostrou o quanto os alunos estão receptivos à tecnologia. Foi motivador ver seu empenho para realizar os cálculos na tela do computador, o que, segundo as professoras, não pode ser observado com tanto entusiasmo quando os mesmos cálculos são propostos no caderno. Os relatos das professoras também foram muito positivos, pois elas fizeram reflexões sobre suas próprias metodologias de ensino, assentindo que aulas práticas no laboratório de informática são mais apreciadas pelos alunos. Ambas afirmaram, ao final do projeto, que continuarão a usar o simulador PhET com seus alunos.

Evidenciamos que as simulações apresentadas pelo PhET são de grande valia para o aprendizado. No site, várias e várias simulações interativas (seja na matemática, física, ciências ou química) estão disponíveis, mas, cabe à escola e aos professores aproveitarem os materiais prontos que a tecnologia disponibiliza. A experiência com o uso do simulador PhET para aprendizado da tabuada com a escola, demonstrou que diferencial para motivar os alunos está a nosso alcance: basta boa vontade, 
planejamento, atitude e reflexão para mudar e inovar o ensino/aprendizado. Dessa forma, espera-se que os professores e professoras que conhecemos naquela escola possam fazer uso contínuo do simulador, bem como buscar muitos outros recursos que a tecnologia oferece para a escola.

\section{Em tempo...}

Retornamos à a escola no semestre seguinte ao desenvolvimento do projeto. Em junho de 2017, participamos de uma Aula de Trabalho Pedagógico Coletivo (a ATPC). Na ocasião, a realização e aplicação do projeto para o ensino de tabuada foi descrita, e o simulador $\mathrm{PhET}$ foi apresentado aos demais professores que não participaram da ação. Em seguida, as professoras que participaram do projeto deram depoimentos muito positivos a respeito do uso do simulador, momento em que os demais professores puderam expor seus questionamentos e elogios. Vale destacar a fala de uma professora que, além de ministrar aulas no primeiro ciclo do ensino fundamental, também é professora de matemática para o sexto ano: para ela, se os alunos que estão hoje no sexto ano tivessem contato com o simulador quando estavam no terceiro ou quarto ano, talvez tivessem tomado gosto pela tabuada e, hoje, estariam mais aptos e dispostos a aprender os conteúdos elencados para seu ano escolar.

Por fim, a diretora da unidade escolar deu seu depoimento e se mostrou muito satisfeita com a realização do projeto. Além disso, mostrou os resultados obtidos na avaliação externa que a escola participou no mês de fevereiro deste ano de 2017 (Avalia Itapê), na qual os alunos do atual quarto ano (que estavam no terceiro ano em 2016), obtiveram melhores resultados nas questões matemáticas do que os alunos do atual quinto ano. Isso, segundo a diretora, mostra que o avanço alcançado pelos alunos se deu devido ao treino da tabuada, graças ao uso da tecnologia e do simulador PhET.

Da nossa parte, todos os pontos positivos observados e indicados apenas nos servem para continuar investigando dessa forma: dentro das escolas, em parceria com direção, professores e alunos. Parece que, trabalhando em conjunto, a educação avança.

\section{REFERÊNCIAS}

FORTUNATO, I. Ensinando futuros professores sobre literatura infantil: relato de experiência. ETD, Campinas, v. 18, n. 3, p. 710-718, 2016. 
MARTINS, Z. As TIC no ensino-aprendizagem de Matemática. X Congresso Internacional Galego-Português de Psicopedagogia, Universidade do Minho. Braga: Anais... 2009.

MORAN, J. Mudando a educação com metodologias ativas. In: SOUZA, C. A.; MORALES, O. E. T. (org.). Convergências Midiáticas, Educação e Cidadania: aproximações jovens. Vol. II. PG: Foca Foto-PROEX/UEPG, 2015.

MORAN, J. A Educação que desejamos: novos desafios e como chegar lá. $5^{\text {a }}$ ed. Campinas: Papirus, 2007.

FEITOSA, R. A.; DIAS, A. M. I. Décadas do surgimento do practicum reflexivo: por teoria(s) e prática(s) articuladas na formação e na ação docentes. In: SHIGUNOV NETO, A.; FORTUNATO, I. 20 anos sem Donald Schön: o que aconteceu com o professor reflexivo?. São Paulo: Edições Hipótese, 2017. p. 13-32.

SILVA, L. A. O Uso pedagógico de mídias na escola: práticas inovadoras. Revista Eletrônica de Educação de Alagoas, Maceió, v. 1, n. 1, p. 119-128, 2013.

SOUZA, D. O. Ensino de matemática com o uso das TIC. Monografia (especialização em mídias na educação). Centro Interdisciplinar de Novas Tecnologias na Educação. Porto Alegre: Universidade Federal do Rio Grande do Sul, 2015.

\section{Como referenciar este artigo}

FALCHI, Lilian de Fatima Oliveira; FORTUNATO, Ivan. Simulador PHET e o ensino da tabuada na educação básica: relato de experiência. Revista on line de Política e Gestão Educacional, Araraquara, v. 22, n. 1, p. 439-452, jan./abr., 2018. E-ISSN:15199029. DOI: 10.22633/rpge.v22.n.1.2018.10672

Submetido em: 18/11/2017

Aprovado em: 28/12/2017 